\title{
Theoretical Analysis of an Amperometric Biosensor Based on Parallel Substrates Conversion
}

\author{
T. Praveen and L. Rajendran \\ Department of Mathematics, The Madura College, Madurai, Tamil Nadu 625 011, India \\ Correspondence should be addressed to L. Rajendran; raj_sms@rediffmail.com
}

Received 5 February 2014; Accepted 12 March 2014; Published 10 April 2014

Academic Editors: S. Arya, R. Kizek, and A. Walcarius

Copyright (C) 2014 T. Praveen and L. Rajendran. This is an open access article distributed under the Creative Commons Attribution License, which permits unrestricted use, distribution, and reproduction in any medium, provided the original work is properly cited.

\begin{abstract}
The behaviour of an amperometric biosensor based on parallel substrates conversion for steady-state condition has been discussed. This analysis contains a nonlinear term related to enzyme kinetics. Simple and closed form of analytical expressions of concentrations and of biosensor current is derived. This model was originally reported by Vytautas Aseris and his team (2012). Concentrations of substrate and product are expressed in terms of single dimensionless parameter. A new approach to Homotopy perturbation method (HPM) is employed to solve the system of nonlinear reaction diffusion equations. Furthermore, in this work, the numerical solution of the problem is also reported using Matlab program. The analytical results are compared with the numerical results. The analytical result provided is reliable and efficient to understand the behavior of the system.
\end{abstract}

\section{Introduction}

A biosensor is an analytical device, used for the detection of an analyte, which combines a biological component with a physiochemical detector [1]. Analyzed substrate is biochemically converted to a product when the biosensor operation is being undertaken. In most of the cases, biosensor response is directly proportional to the concentration of the reaction product [2]. The amperometric biosensors have proved to be reliable in various systems with applications in the field of medicine, food technology, and the environmental industry $[3,4]$. The understanding of the kinetic peculiarities of biosensors is of crucial importance for their design. The mathematical modeling is rather widely used to improve the efficiency of the biosensors design and to optimize their configuration [5-8]. Since 1970s, various mathematical models of biosensors have been developed and used successfully to study and optimize analytical characteristics of biosensors [9-14]. Mathematical modeling of two-enzyme biosensors has been started in 1980s with the modeling of an amperometric monolayer enzyme electrode with two coimmobilized enzymes $[15,16]$. Later, nonlinear mathematical models have been developed for amperometric two-enzyme biosensors with different enzymes $[17,18]$.

The numerical method of solving partial differential equations is to make calculation at all intervals of substrates concentration and at different diffusion and enzymatic reaction rates. The nonstationary diffusion equations [19], containing a nonlinear term related to the enzymatic reaction, are carried out using the implicit difference scheme [20]. In recent years, analytical solutions are reported for various types of biosensors [21-27].

To the best of our knowledge, there is no simple analytical expression for steady-state concentrations and current of amperometric-based biosensor utilizing parallel substrates conversion for all values of parameters. In this paper, we present the simple and closed form of the analytical expressions for the concentrations of substrate and of product using new Homotopy perturbation method (HPM) [28]. The current density was determined corresponding to all possible values of the parameters.

\section{Mathematical Formulation of the Problem and Analysis}

The reaction scheme employing two parallel substrates $\left(S_{1}\right.$ and $S_{2}$ ), two enzymes $\left(E_{1}\right.$ and $\left.E_{2}\right)$, and two reaction products $\left(P_{1}\right.$ and $\left.P_{2}\right)$ in biosensor may be as follows:

$$
\begin{gathered}
S_{1} \stackrel{E_{1}}{\longrightarrow} \frac{1}{2} P_{1}, \\
S_{1}+S_{2} \stackrel{E_{2}}{\longrightarrow} P_{2} .
\end{gathered}
$$


First phase of the biosensor action contains hydrogen peroxide $\left(S_{1}\right)$ only. The biosensor response reaches the steadystate at the end of the first phase. The second phase of the biosensor action begins at the second substrate $\left(S_{2}\right)$ poured into the solution. The relative changes between the responses in both phases are measured as the final response of the biosensor. The schematic diagram of the system is provided in Figure 1. The above reaction in the enzymatic layer with the one-dimensional-in-space diffusion, described by Fick's law, leads to the following nonlinear transient reaction-diffusion equations [29]:

$$
\begin{gathered}
D_{S_{1, e}} \frac{\partial^{2} S_{1, e}}{\partial x^{2}}-k_{1} e_{1} S_{1, e}-\frac{k_{21} k_{22} e_{2} S_{1, e} S_{2, e}}{k_{21} S_{1, e}+k_{22} S_{2, e}}=0, \\
D_{S_{2, e}} \frac{\partial^{2} S_{2, e}}{\partial x^{2}}-\frac{k_{21} k_{22} e_{2} S_{1, e} S_{2, e}}{k_{21} S_{1, e}+k_{22} S_{2, e}}=0, \\
D_{P_{1, e}} \frac{\partial^{2} P_{1, e}}{\partial x^{2}}+\frac{k_{1} e_{1} S_{1, e}}{2}=0, \\
D_{P_{2, e}} \frac{\partial^{2} P_{2, e}}{\partial x^{2}}+\frac{k_{21} k_{22} e_{2} S_{1, e} S_{2, e}}{k_{21} S_{1, e}+k_{22} S_{2, e}}=0,
\end{gathered}
$$

where $x$ denotes space, $S_{1, e}, S_{2, e}$ are the molar concentration of the substrates, and $P_{1, e}, P_{2, e}$ are the molar concentration of products. $D_{S_{1, e}}, D_{S_{2, e}}, D_{P_{1, e}}$, and $D_{P_{2, e}}$ are the corresponding diffusion coefficients and $k_{1}, k_{21}$, and $k_{22}$ are the reaction rate constants. Graphical representation of the products $P_{1, e}$, $P_{2, e}$ and substrates $S_{1, e}, S_{2, e}$, with steady-state boundary conditions employed in the simulated multilayered biosensor is provided in Figure 2. The mass transport by diffusion of the substrates and products takes place outside the enzyme layer. The diffusion layer is treated as the Nernst diffusion layer. The boundary conditions for the above system of nonlinear equation are as follows:

$$
\begin{gathered}
\left.D_{C_{e}} \frac{\partial c_{e}}{\partial x}\right|_{x=0}=0, \quad P_{1, e}(x=0)=0, \quad c=S_{1}, S_{2}, P_{2} \\
S_{i, e}\left(x=d_{e}+d_{d}\right)=S_{i 0}, \quad P_{i, e}\left(x=d_{e}+d_{d}\right)=0, \quad i=1,2,
\end{gathered}
$$

where $d_{e}$ and $d_{d}$ denote the thickness of the enzyme and diffusion layer. For the steady-state condition, the following sets of dimensionless variables are introduced:

$$
\begin{gathered}
S_{1 N}=\frac{S_{1, e}}{S_{10}}, \quad S_{2 N}=\frac{S_{2, e}}{S_{20}}, \\
P_{1 N}=\frac{P_{1, e}}{S_{10}}, \quad P_{2 N}=\frac{P_{2, e}}{S_{10}}, \\
y=\frac{x}{d}, \quad \gamma_{S 1}=\frac{d^{2} k_{1} e_{1}}{D_{S_{1, e}}}, \quad \gamma_{S 2}=\frac{d^{2} k_{22} e_{2}}{D_{S_{1, e}}}, \\
\gamma_{S 3}=\frac{d^{2} k_{22} e_{2}}{D_{S_{2, e}}}, \quad \gamma_{P 1}=\frac{d^{2} k_{1} e_{1}}{D_{P_{1, e}}}, \quad \gamma_{P 2}=\frac{d^{2} k_{1} e_{1}}{D_{P_{2, e}}}, \\
\alpha=\frac{S_{10}}{S_{20}}, \quad \beta=\frac{k_{22}}{k_{21}},
\end{gathered}
$$

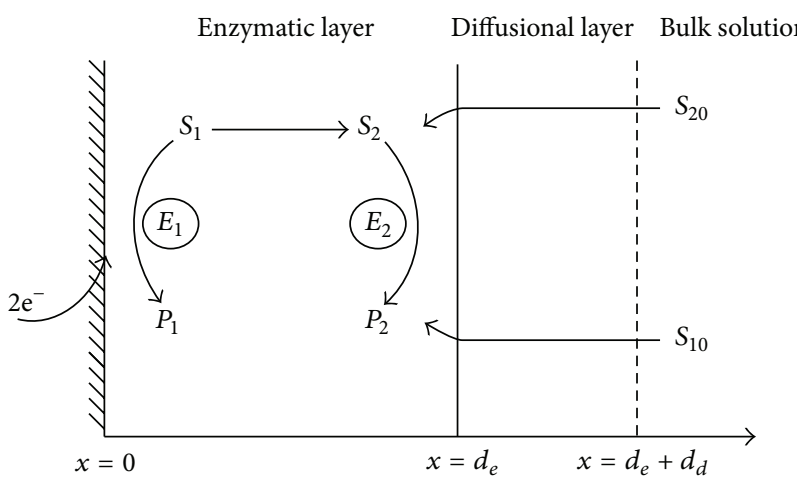

FIGURE 1: Schematic representation of biosensor utilising parallel substrate conversion with enzymatic layer (of thickness $d_{e}$ ) and the diffusional layer (of thickness $d_{d}$ ) the bioelectrode functioning in the presence of hydrogen peroxide $\left(S_{1}\right)$ or catalyses $\left(S_{2}\right) . E_{1}$ and $E_{2}$ represent the catalase and peroxidase activities. $P_{1}$ and $P_{2}$ are products.

where $d=d_{e}+d_{d}$. The governing nonlinear reaction diffusion equations (2) are expressed in the following steadystate nondimensional form:

$$
\begin{gathered}
\frac{d^{2} S_{1 N}}{d y^{2}}=\gamma_{S 1} S_{1 N}+\gamma_{S 2} \frac{S_{1 N} S_{2 N}}{\alpha S_{1 N}+\beta S_{2 N}}, \\
\frac{d^{2} S_{2 N}}{d y^{2}}=\gamma_{S 3} \frac{S_{1 N} S_{2 N}}{\alpha S_{1 N}+\beta S_{2 N}}, \\
\frac{d^{2} P_{1 N}}{d y^{2}}=-\gamma_{P 1} \frac{S_{1 N}}{2}, \\
\frac{d^{2} P_{2 N}}{d y^{2}}=-\gamma_{P 2} \frac{S_{1 N} S_{2 N}}{\alpha S_{1 N}+\beta S_{2 N}}
\end{gathered}
$$

where $S_{1 N}$ and $S_{2 N}$ represent the dimensionless substrate concentrations, $P_{1 N}$ and $P_{2 N}$ represent the dimensionless product concentrations, and $y$ represents the dimensionless distance. The reaction/diffusion parameters of substrates and products are considered to be $\gamma_{S 1}, \gamma_{S 2}, \gamma_{S 3}, \gamma_{P 1}$, and $\gamma_{P 2}$. The boundary conditions are represented as follows:

$$
\begin{gathered}
\frac{d S_{1 N}}{d y}=\frac{d S_{2 N}}{d y}=\frac{d P_{2 N}}{d y}=0, \quad P_{1 N}=0 \quad \text { when } y=0, \\
S_{1 N}=S_{2 N}=1, \quad P_{1 N}=P_{2 N}=0 \quad \text { when } y=1 .
\end{gathered}
$$

The dimensionless current density is given by

$$
\psi=\frac{i_{s} d}{n_{e} F D_{P 1, e} A S_{10}}=\left.\frac{d P_{1 N}}{d y}\right|_{y=0} .
$$

\section{A New Approach to Homotopy Perturbation Method and Its Advantages}

The Homotopy perturbation method is first introduced to solve nonlinear wave equations. The advantage of the method is that it does not need a small parameter in the system, leading to wide application in nonlinear wave equations [30]. Recently, many authors have used HPM to various 


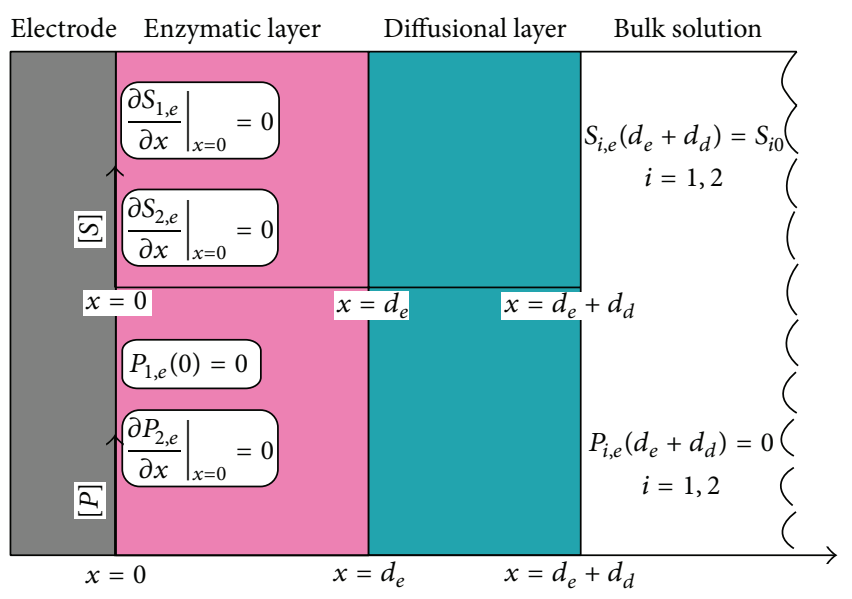

FIGURE 2: Graphical representation of steady-state boundary conditions of the products $P_{1, e}, P_{2, e}$ and substrates $S_{1, e}, S_{2, e}$, for multilayered biosensor. Here, $x=0$ is taken at the surface of the electrode and $x=d_{e}+d_{d}$ is taken as the surface of the diffusional layer.

problems and reported the efficiency of the HPM for handling nonlinear engineering problems [31-34]. This method is a combination of Homotopy in topology and classic perturbation techniques. He used the HPM to solve the Light hill equation [35]; this wide variety of applications shows the power of the HPM to solve functional equations. The HPM has uniqueness in its applicability, accuracy, and efficiency. Recently, a new approach to HPM is introduced to solve the nonlinear problem, in which one will get better simple approximate solution in the zeroth iteration [28].

\section{Analytical Expression for the Concentration of Substrate and Product Using New Homotopy Perturbation Method}

In this paper, a new approach to Homotopy perturbation method is used (Appendix A) to solve the nonlinear differential equations (5)-(8). Using this method, the analytical expression of the two substrate concentrations $\left(S_{1 N}\right.$ and $\left.S_{2 N}\right)$ and two product concentrations $\left(P_{1 N}\right.$ and $\left.P_{2 N}\right)$ can be obtained as follows:

$$
\begin{gathered}
S_{1 N}(y)=\frac{\cosh (A y)}{\cosh (A)}, \\
S_{2 N}(y)=\frac{\cosh (B y)}{\cosh (B)}, \\
P_{1 N}(y)=\frac{\gamma_{P 1}[1-\cosh (A y)+y \cosh (A)-y]}{2 A^{2} \cosh (A)} \\
P_{2 N}(y)=\frac{\gamma_{P 2}}{\gamma_{S 3}}\left[1-\frac{\cosh (B y)}{\cosh (B)}\right],
\end{gathered}
$$

where

$$
A=\sqrt{\frac{\gamma_{S 1}(\alpha+\beta)+\gamma_{S 2}}{\alpha+\beta}}, \quad B=\sqrt{\frac{\gamma_{S 3}}{\alpha+\beta}} .
$$

Equations (11)-(14) satisfy the boundary conditions (9). These equations represent the simple and closed form of analytical expressions of concentrations of substrate and product for all possible values of the parameters. Using (6) and (8) with boundary conditions (9), the following relation is also obtained:

$$
P_{2 N}(y)=\frac{\gamma_{P 2}}{\gamma_{S 3}}\left[1-S_{2 N}(y)\right]
$$

The analytical expression of the current using (10) is as follows:

$$
\psi=\frac{i d}{n_{e} F A D_{P_{1, e}} S_{10}}=\frac{\gamma_{P 1}[\cosh (A)-1]}{2 A^{2} \cosh (A)} .
$$

When $A \rightarrow 0$, the above expression can be simplified as $\psi=$ $\gamma_{P 1} / 4$

4.1. Limiting Case. The mathematical as well as the corresponding computational models of the biosensor were evaluated. Assume that zero concentration of the second substrate $\left(S_{20}=0\right)$ leads to reducing the governing equations (5)-(8) to the following equations:

$$
\begin{gathered}
\frac{d^{2} S_{1 N}}{d y^{2}}=\gamma_{S 1} S_{1 N}, \\
\frac{d^{2} P_{1 N}}{d y^{2}}=-\gamma_{P 1} \frac{S_{1 N}}{2} .
\end{gathered}
$$

The steady-state solution of the above equations for the boundary condition (9) is given by

$$
\begin{gathered}
S_{1, N}=\frac{\cosh \left(\sqrt{\gamma_{S 1}} y\right)}{\cosh \left(\sqrt{\gamma_{S 1}}\right)}, \\
P_{1 N}(y)=\frac{\gamma_{P 1}\left[1-\cosh \left(\sqrt{\gamma_{S 1}} y\right)+y \cosh \left(\sqrt{\gamma_{S 1}}\right)-y\right]}{2 \gamma_{S 1} \cosh \left(\sqrt{\gamma_{S 1}}\right)} .
\end{gathered}
$$

The dimensionless steady-state current using (10) is given by

$$
\psi=\frac{i d}{n_{e} F A D_{P_{1, e}} S_{10}}=\frac{\gamma_{P 1}\left[\cosh \left(\sqrt{\gamma_{S 1}}\right)-1\right]}{2 A^{2} \cosh \left(\sqrt{\gamma_{S 1}}\right)} .
$$

Equation (20) is identical to (17), when $S_{20}=0$ (i.e., $\alpha=\infty$ ) in (17).

\section{Comparison of Analytical Expressions with Experimental Work and Numerical Simulation}

To show the efficiency, the steady-state result (11)-(14) of the reaction diffusion equations is compared with the numerical solution of (5)-(8). The numerical solutions are found using pdepe (finite element method) in Matlab [36]. This Matlab program [37] is also given in Appendix B. The comparison is shown in Figures 3-6 and it gives satisfactory agreement. 


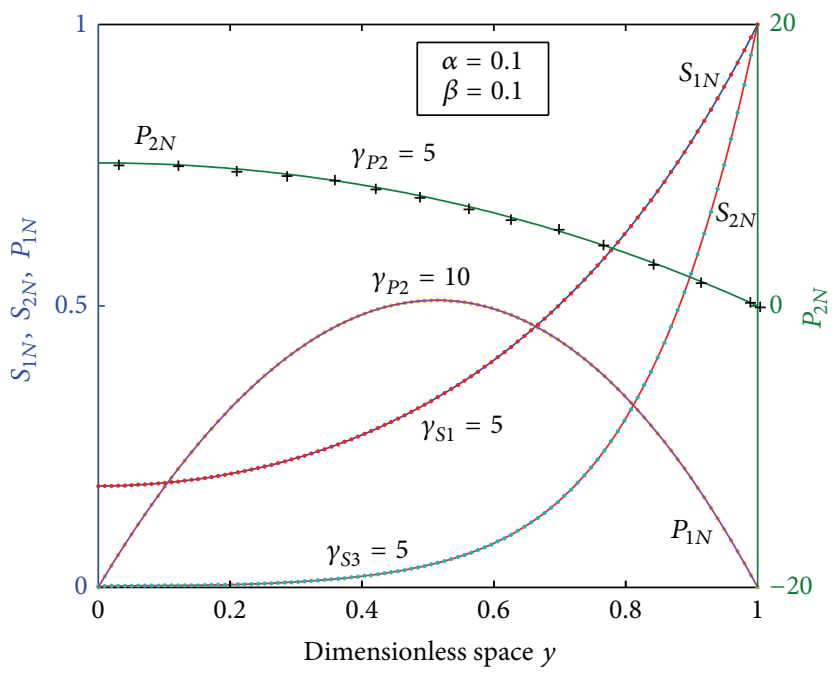

FIGURE 3: Normalized substrates and products concentration versus dimensionless space $y$ were computed using (11)-(14) for various values

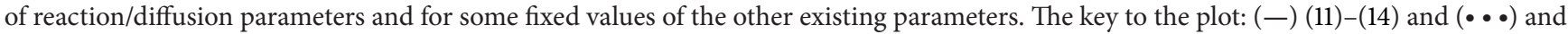
$(+++)$ numerical simulation of $(5)-(8)$.

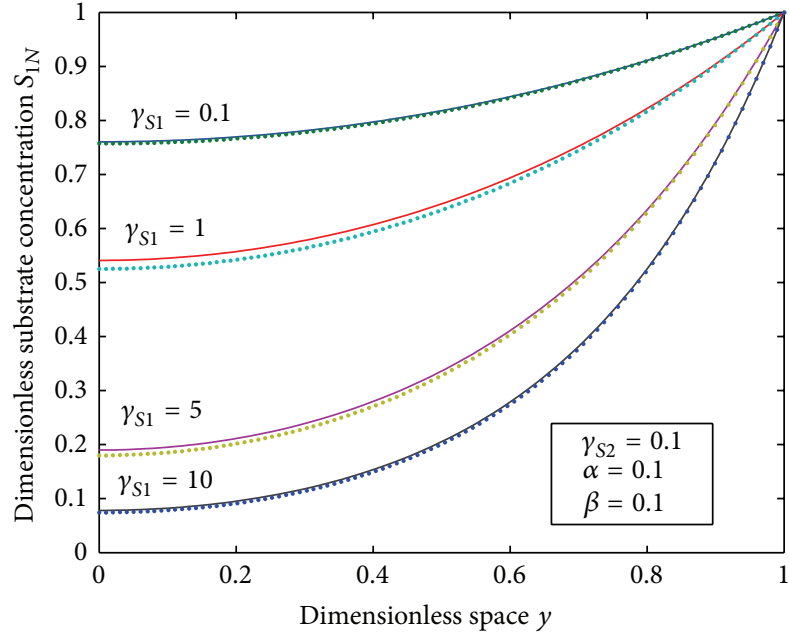

(a)

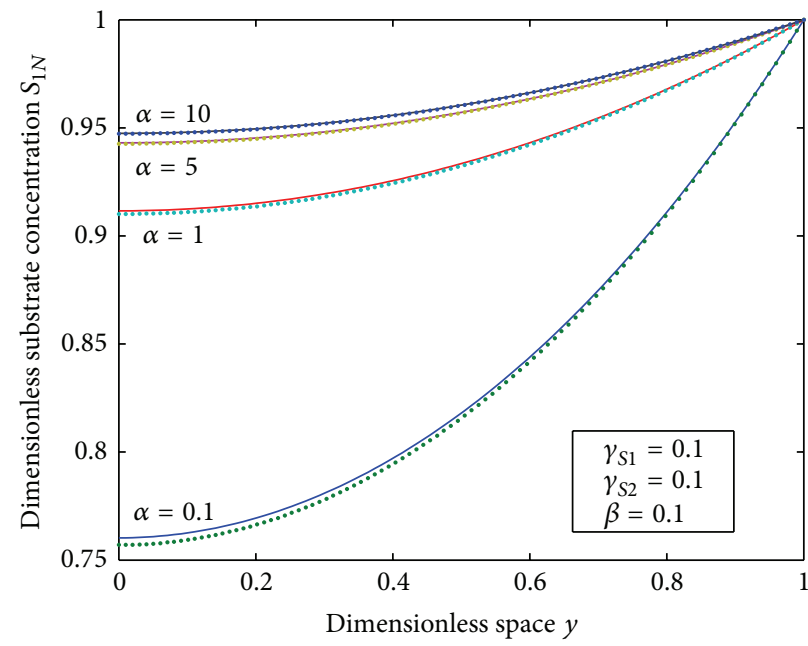

(c)

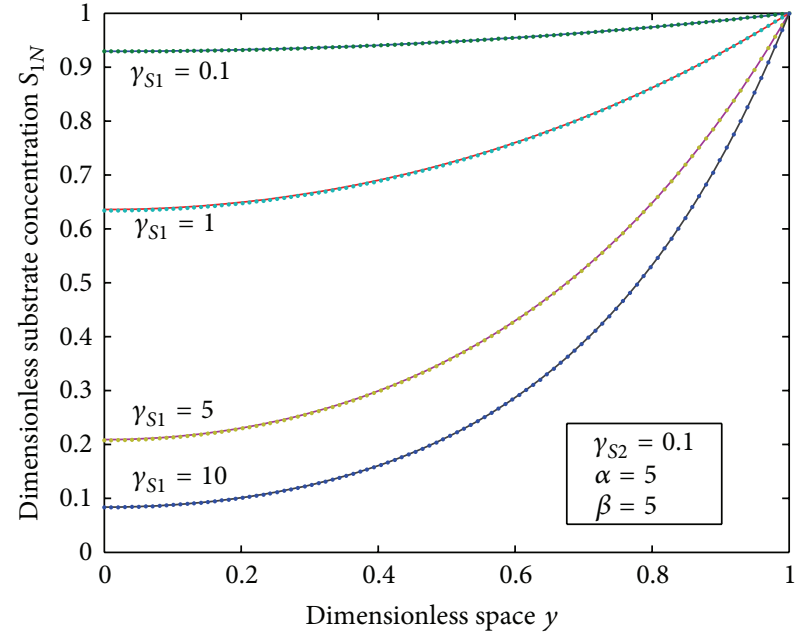

(b)

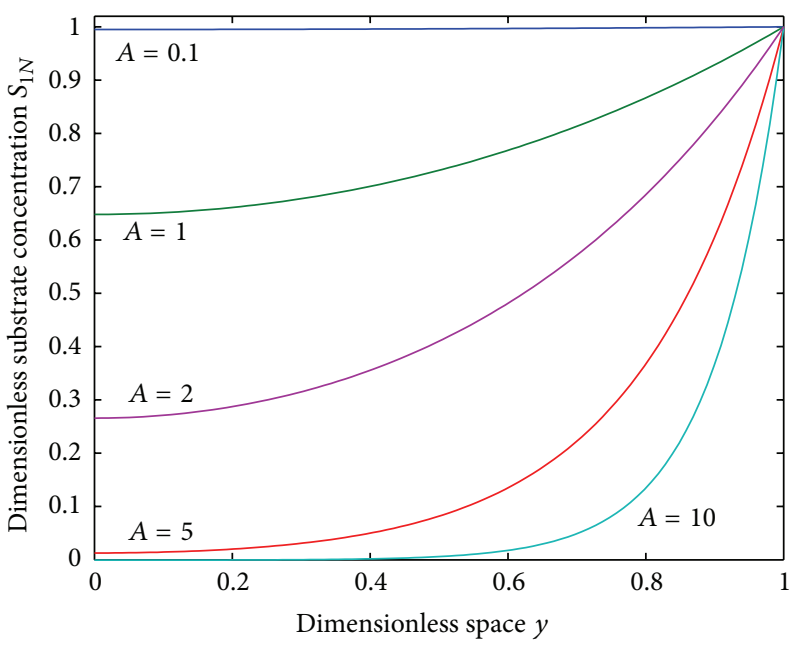

(d)

Figure 4: Normalized substrate concentration $S_{1 N}$ versus dimensionless space $y$ was computed using (11) for various values of reaction/diffusion parameter $\gamma_{S 1}$, dimensionless parameter $\alpha$ and for some fixed values of the parameters $\gamma_{S 1}, \gamma_{S 2}, \alpha, \beta$. The key to the plot: $(-)(11)$ and $(\bullet \bullet)$ numerical simulation of (5). 


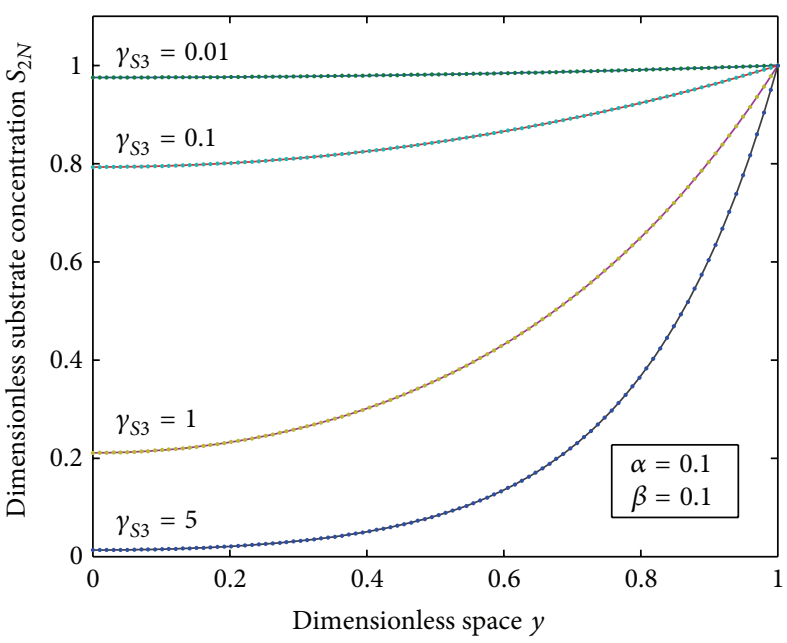

(a)

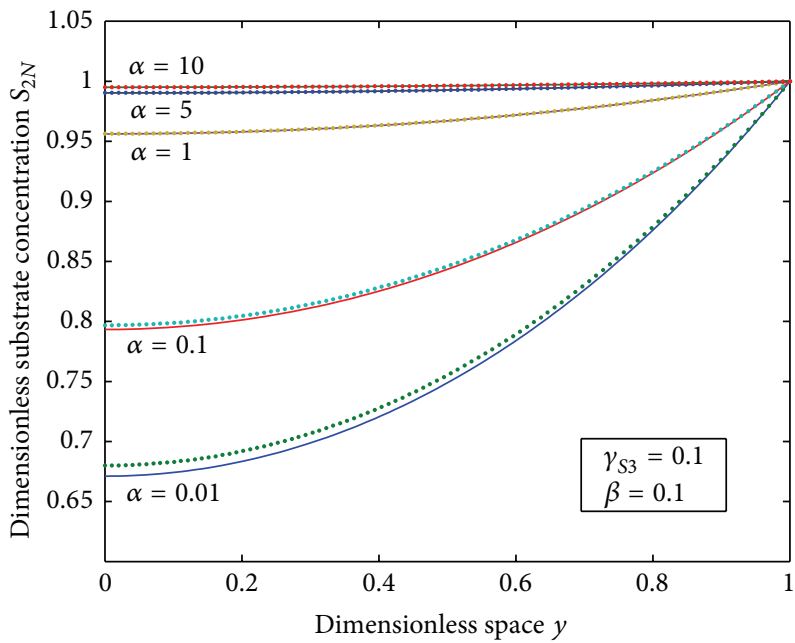

(c)

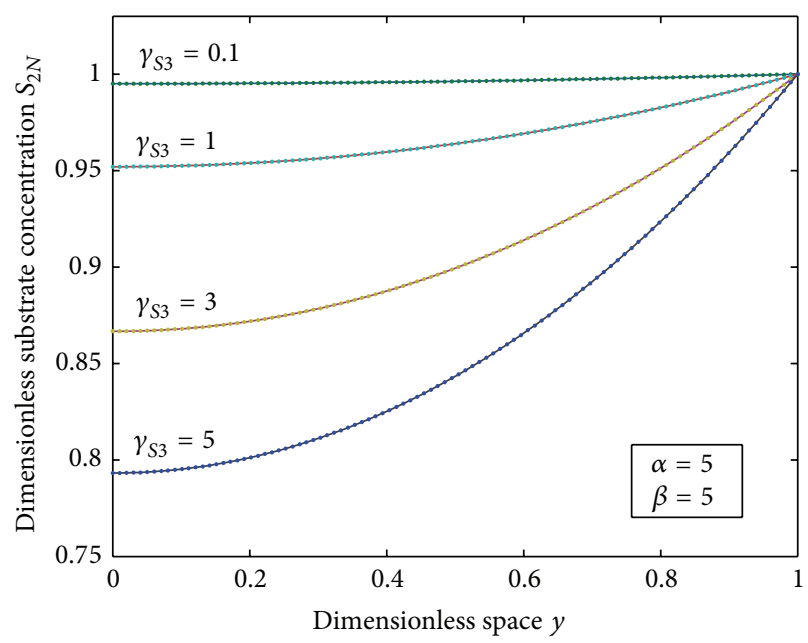

(b)

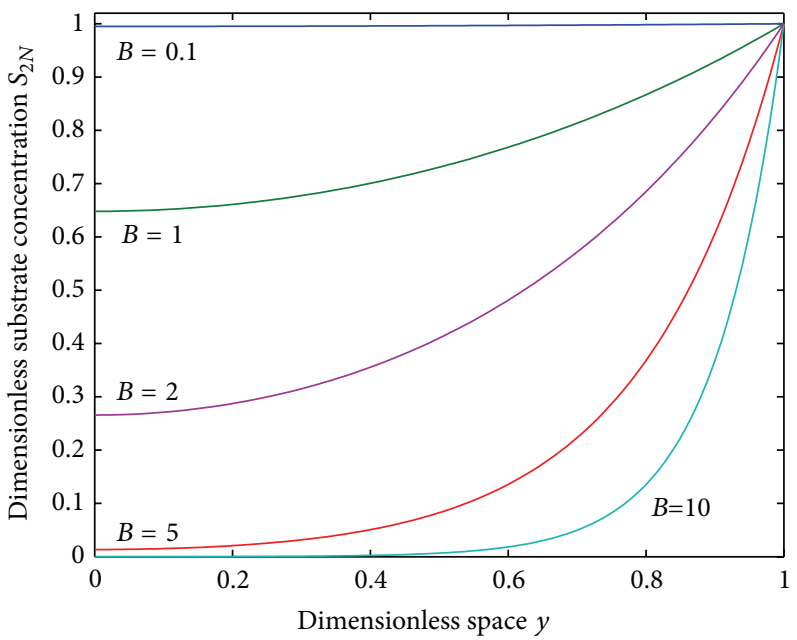

(d)

Figure 5: Normalized substrate concentration $S_{2 N}$ versus dimensionless space $y$ was computed using (12) for various values of reaction/diffusion parameter $\gamma_{S 3}$, dimensionless parameter $\alpha$ and for some fixed values of the parameters $\alpha, \beta$, $\gamma_{S 3}$. The key to the plot: ( -$)$ $(12)$ and $(\bullet \bullet)$ numerical simulation of $(6)$.

\section{Discussion}

Equations (11)-(14) are the new simple and closed approximate analytical expressions for the dimensionless substrate concentrations $\left(S_{1 N}\right.$ and $\left.S_{2 N}\right)$ and product concentrations $\left(P_{1 N}\right.$ and $\left.P_{2 N}\right)$ in terms of $A$ or $B$. The analytical results (11)-(14) are compared with numerical solution, which is provided in Figures 3-7. Figure 3 shows the plots of all the concentration versus dimensionless distance $y$.

The kinetic response of a biosensor depends on the concentration species. The concentration depends on the following factors: $\gamma_{S 1}, \gamma_{S 2}, \gamma_{S 3}, \gamma_{P 1}$, and $\gamma_{P 2}$. The diffusion parameters $\gamma_{S 1}$ and $\gamma_{S 3}$ represent the ratio of the characteristic time of the enzymatic reaction to that of concentration diffusion. These parameters can be varied by changing the thickness of the enzyme or diffusional layer. These parameters describe the relative importance of diffusion and reaction in both layers. When $\gamma_{S 1}$ or $\gamma_{S 3}$ is small, the kinetics is dominant resistance; the uptake of concentration species is kinetically controlled. Under these conditions, the concentration species across both the layers is essentially uniform. When the diffusion parameter $\gamma_{S 1}$ or $\gamma_{S 3}$ is large, diffusion limitations are the principal determining factor.

Figures 4 and 5 show the dimensionless concentration of substrates $\left(S_{1 N}\right.$ and $\left.S_{2 N}\right)$ versus dimensionless distance $y$. Figures 3 and 4(a) and 4(b) are plotted for various values of diffusion parameters $\gamma_{S 1}$ and $\gamma_{S 3}$ for some fixed values of $\alpha, \beta$ and $\gamma_{S 2}$. From these figures, it is clear that the concentration of substrates $S_{1 N}$ and $S_{2 N}$ decreases when the value of $\gamma_{S 1}$ and $\gamma_{S 3}$ increases, respectively. The concentration is approximately equal to one when $\gamma_{S 1} \leq 0.01$ and $\gamma_{S 3} \leq$ 0.01 . Figures $4(\mathrm{c})$ and 5(c) are plotted for various values of dimensionless parameter $\alpha$ for some fixed values of other existing parameters. From these figures, it is clear that concentration increases for large values of $\alpha$. Figures $4(\mathrm{~d})$ and 5(d) are plotted for various values of $A$ and $B$, respectively. It 


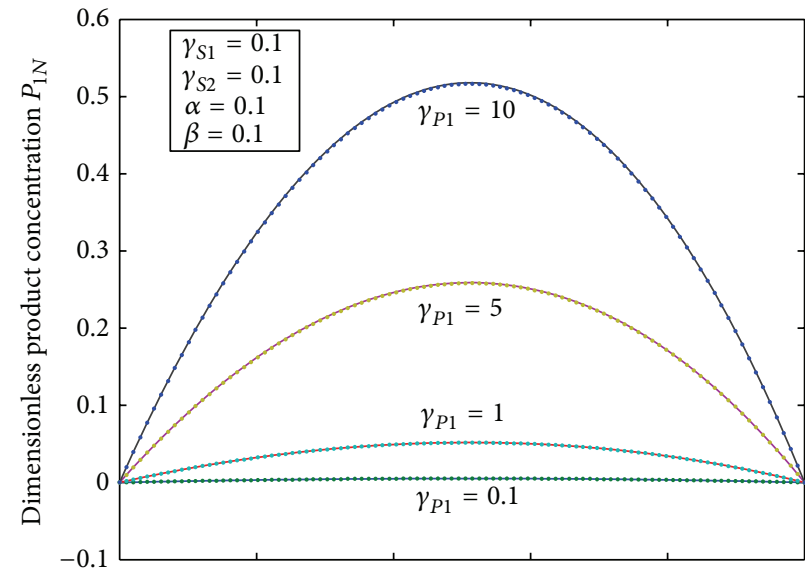

(a)

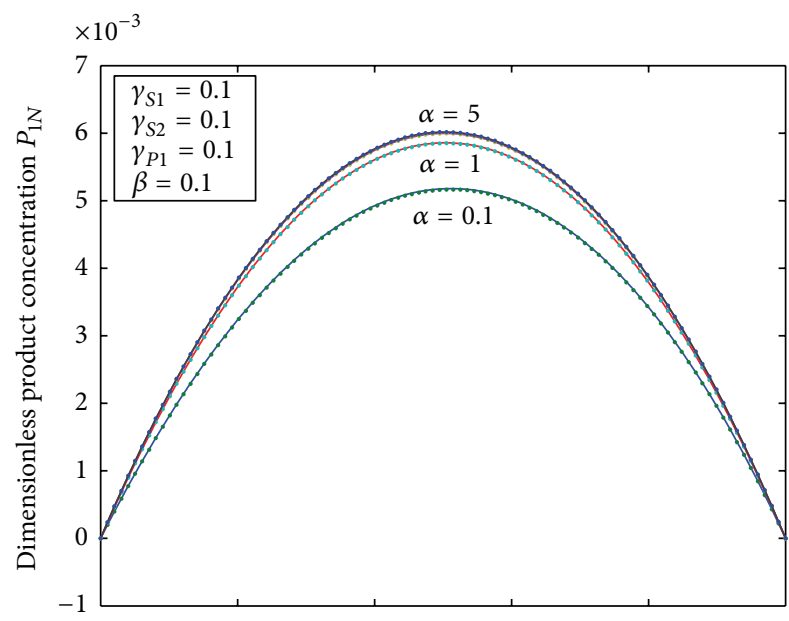

(c)

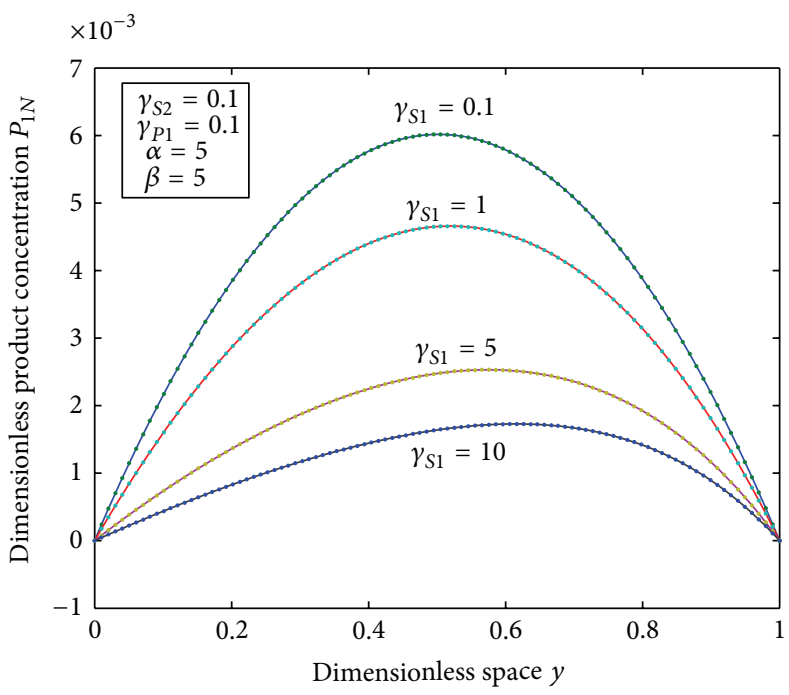

(e)

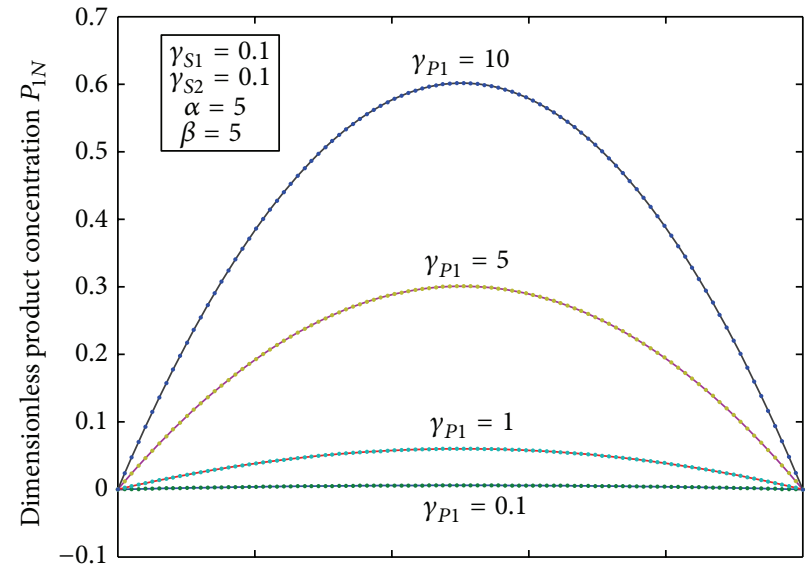

(b)

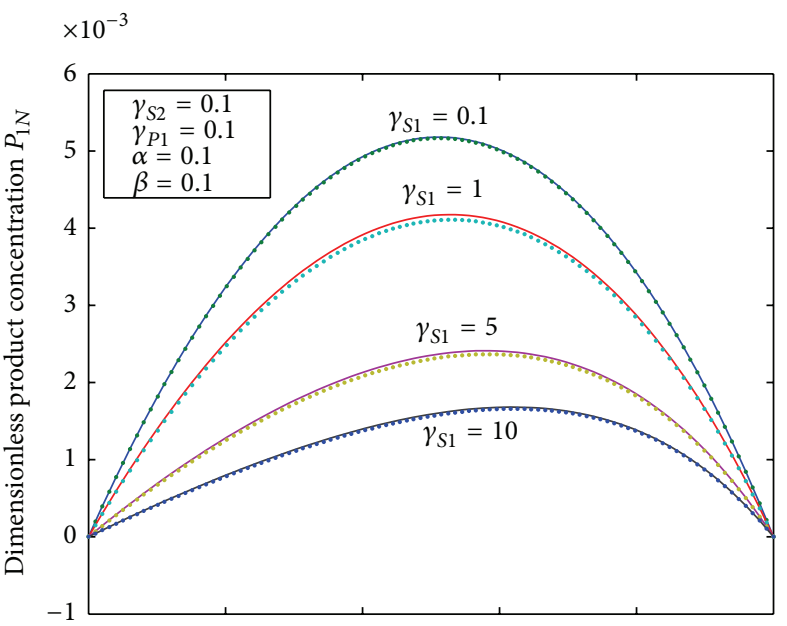

(d)

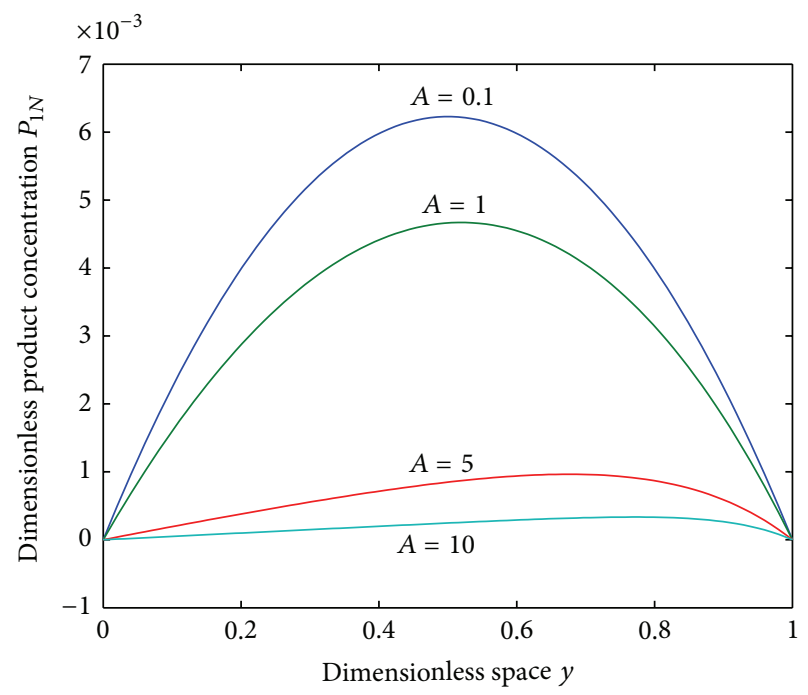

(f)

FIGURE 6: Normalized product concentration $P_{1 N}$ versus dimensionless space $y$ was computed using (13) for various values of reaction/diffusion parameter $\gamma_{P 1}, \gamma_{S 1}$ and for some fixed values of the parameters $\gamma_{S 1}, \gamma_{S 2}, \gamma_{P 1}, \alpha, \beta$. The key to the plot: (一) (13) and (•・•) numerical simulation of (7). 


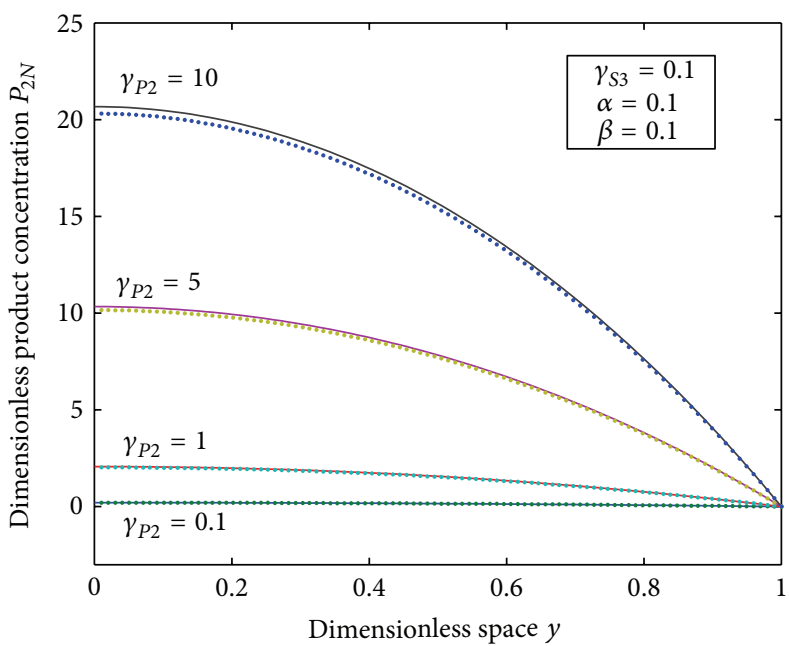

(a)

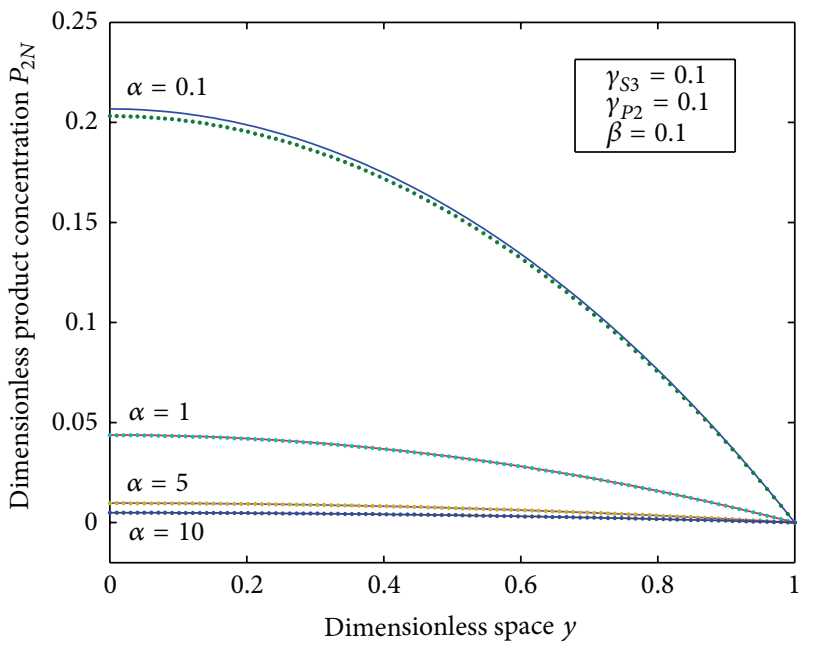

(c)

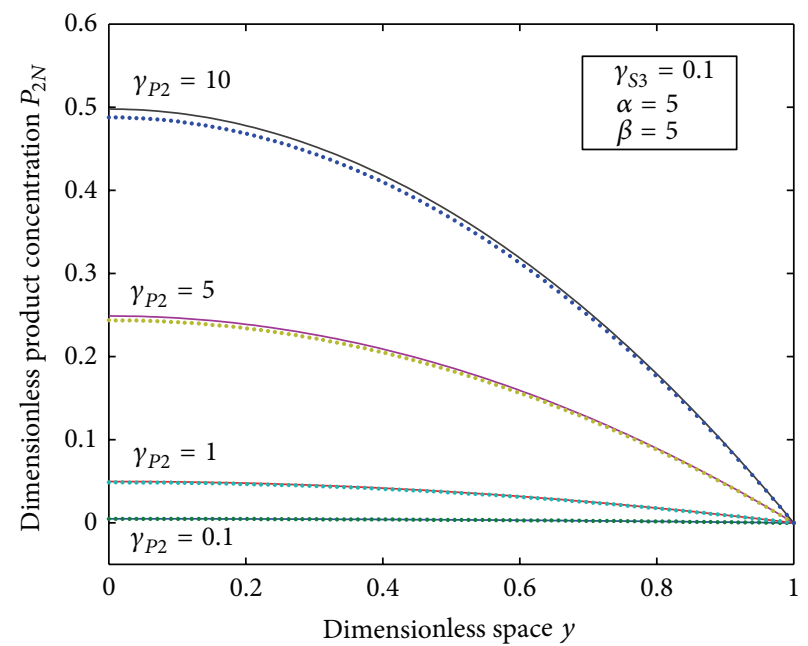

(b)

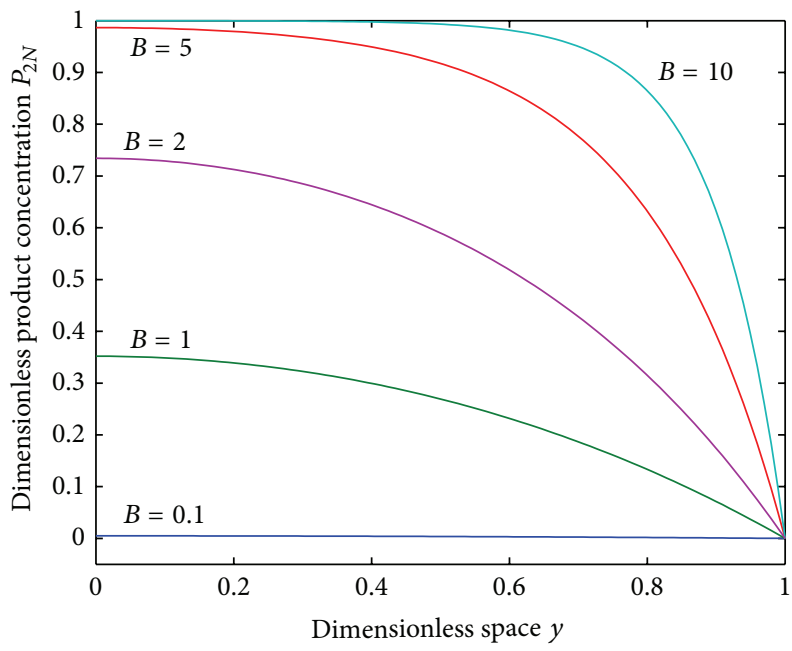

(d)

FIGURE 7: Normalized product concentration $P_{2 N}$ versus dimensionless space $y$ was computed using (14) for various values of reaction/diffusion parameter $\gamma_{P 2}$, dimensionless parameter $\alpha$ and for some fixed values of the parameters $\gamma_{P 1}, \gamma_{S 3}, \alpha, \beta$. The key to the plot: $(-)(14)$ and $(\bullet \bullet)$ numerical simulation of $(8)$.

is evident that the concentration is uniform, when $\gamma_{S 1}(\alpha+\beta)+$ $\gamma_{S 2}<(0.01)(\alpha+\beta)$ (or $\left.A<0.1\right)$ and $\gamma_{S 3}<(0.01)(\alpha+\beta)$ (or $B<0.1)$.

Figures 6(a)-6(f) show the dimensionless product concentration profile $P_{1 N}$ versus dimensionless distance $y$ using (13). Figures 6(a) and 6(b) are plotted for all various values of $\gamma_{P 1}$ for some fixed values of $\alpha, \beta, \gamma_{S 1}$ and $\gamma_{S 2}$. Thus, it is concluded that there is a simultaneous increase in the values of the concentration $P_{1 N}$ as well as in $\gamma_{P 1}$. Figure 6(c) is plotted for various values of $\alpha$ and the fixed value of $\gamma_{S 1}, \gamma_{S 2}$, $\gamma_{P 1}$, and $\beta$. It shows that the concentration is always minimum for all values of $\alpha$. Concentration versus distance is plotted in Figures 6(d) and 6(e) for various values of $\gamma_{S 1}$ and for some fixed values of other existing parameters. Thus, it is concluded that the concentration is always minimum and also there is a simultaneous decrease in the values of the concentration $P_{1 N}$ as the value of $\gamma_{S 1}$ increases. Figure 6(f) is plotted for various values of $A$, and from these graphs, it is inferred that concentration is minimum and uniform when $A \geq 0$.
Figures $7(\mathrm{a})-7(\mathrm{~d})$ are plotted for the dimensionless product concentration $P_{2 N}$ as ordinate versus dimensionless space $y$ as abscissa using (14). From Figures 7(a) and 7(b), it is evident that the concentration of $P_{2 N}$ increases as the diffusivity parameter $\gamma_{P 2}$ increases. The concentration is approximately equal to zero, that is, $\left(P_{2 N} \approx 0\right)$ when $\gamma_{P 2} \leq 0.1$ for all possible values of the parameters $\alpha, \beta$ and $\gamma_{S 3}$. From Figure $7(\mathrm{c})$, it is inferred that concentration $P_{2 N}$ decreases, when the value of $\alpha$ increases and $P_{2 N} \approx 0$ when $\alpha \geq 10$. Figure $7(\mathrm{~d})$ is plotted for various values of $B$; it is evident that the concentration increases as the value of $B$ increases. The concentration increases, when $\gamma_{S 3}>(0.01)(\alpha+\beta)$ or $B>0.1$.

Figures $8(\mathrm{a})-8(\mathrm{e})$ are plotted using (17), which shows the dynamics of normalized steady-state current $\psi$ versus dimensionless parameters $\gamma_{P 1},(\alpha+\beta), \gamma_{S 1}, \gamma_{S 2}$, and $A$, respectively. From Figure $8(\mathrm{a})$, it is noted that, for small values of $\gamma_{S 1}\left(\gamma_{S 1} \leq 0.1\right)$ and for any values of $\alpha$ and $\beta$, the value of the current is significantly high. The current grows notably faster at higher values of $\gamma_{S 1}$ but in the case of $\gamma_{S 1} \geq 10$ and $\alpha=\beta=$ 


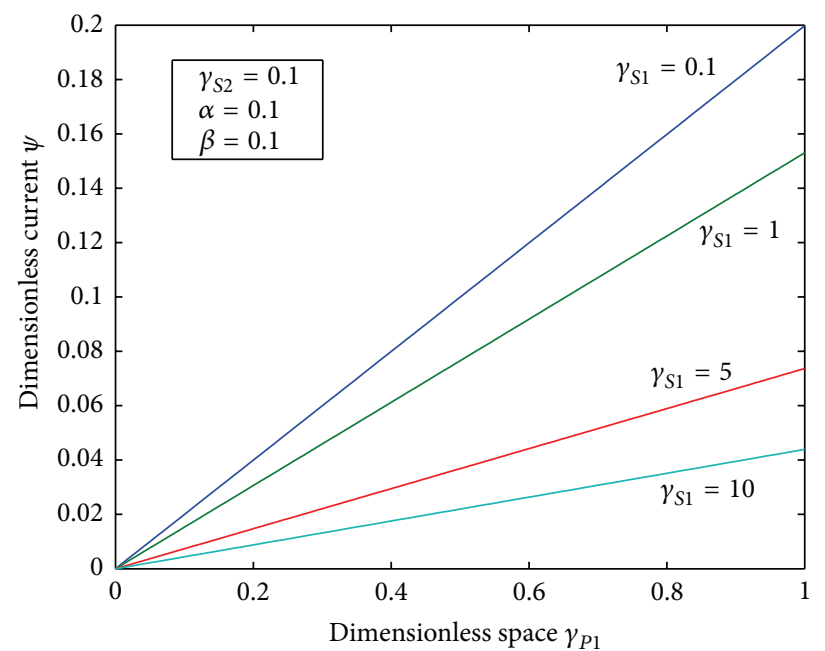

(a)

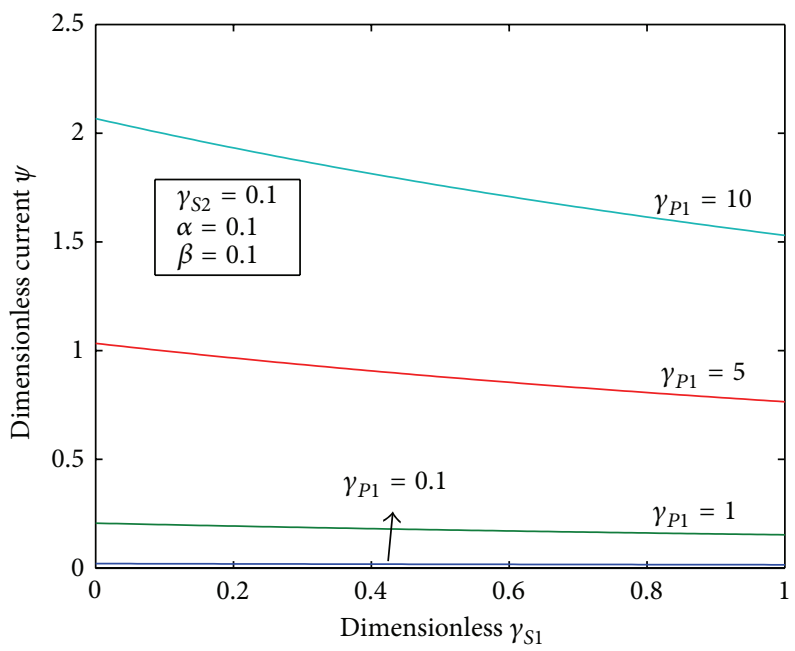

(c)

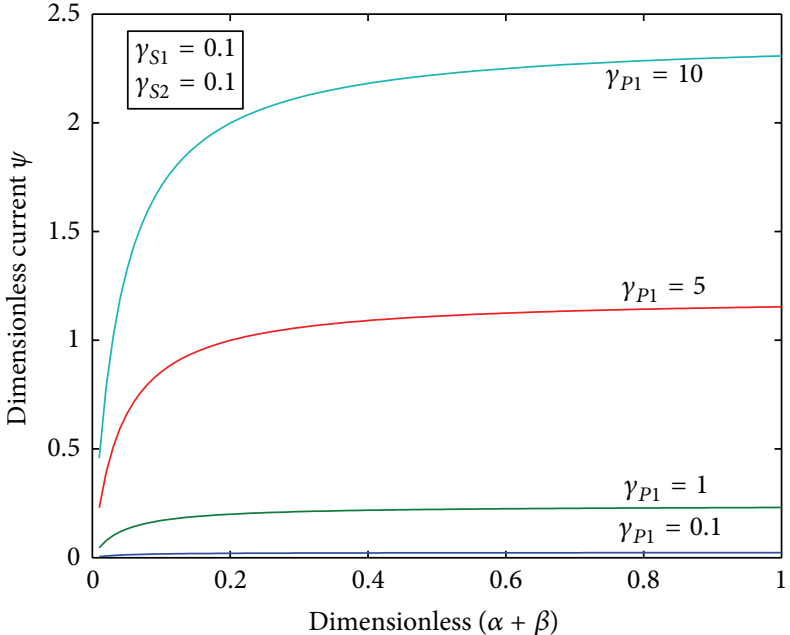

(b)

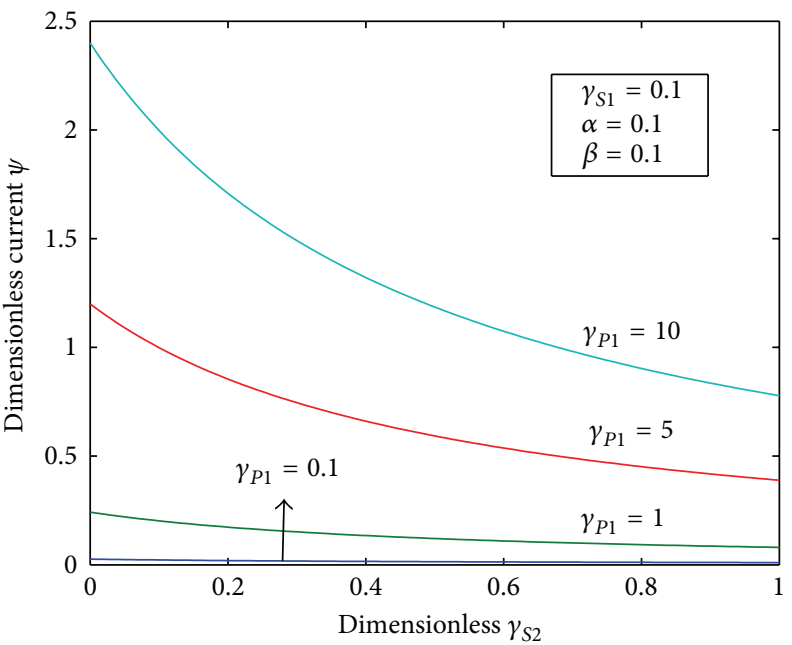

(d)

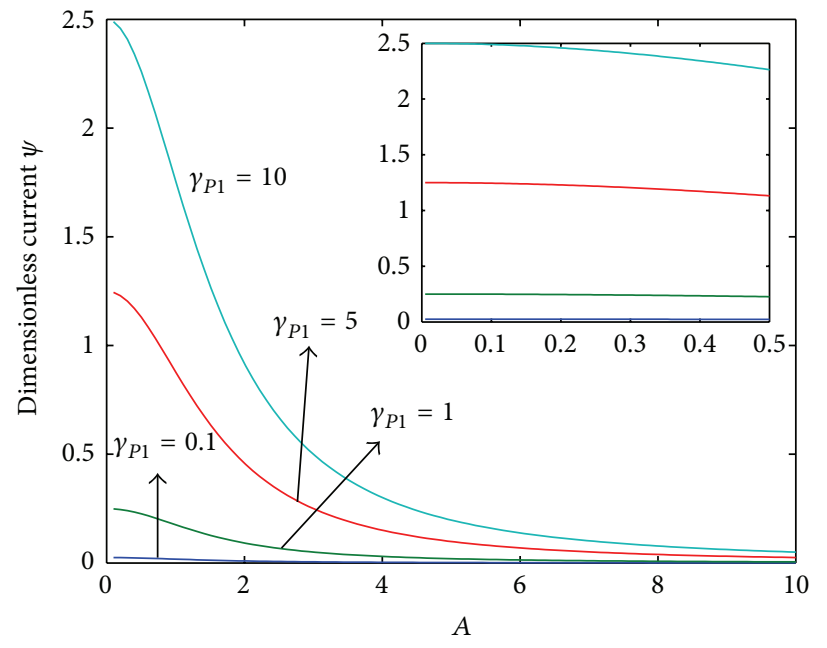

(e)

FIGURE 8: Dimensionless current $\psi$ versus dimensionless parameters $\gamma_{P 1},(\alpha+\beta), \gamma_{S 1}, \gamma_{S 2}$ and $A$ for some fixed values of the other parameters using (17). 
0.1 , the current does not increase. Figure $8(\mathrm{~b})$ is plotted for various values of $\gamma_{P 1}$ and for some fixed values of $\gamma_{S 1}$ and $\gamma_{S 2}$. It is observed that the current increases rapidly and reaches the steady-state when $(\alpha+\beta) \geq 0.5$. From Figures $8(\mathrm{c})$ and $8(\mathrm{~d})$, it is evident that the current is uniformly decreasing for large values of $\gamma_{P 1}$, that is, $\left(\gamma_{P 1} \geq 5\right)$, and constant elsewhere. Figure $8(\mathrm{e})$ is plotted for various values of the reaction/diffusion parameter $\gamma_{P 1}$ as abscissa and normalized steady-state current $\psi$ as ordinate. It is observed that the current increases as the value of $\gamma_{P 1}$ increases. Also current decreases for all values of the reaction/diffusion parameter $\gamma_{P 1}$ and reaches zero when $A \geq 10$.

\section{Conclusion}

Mathematical model, describing the steady-state response of an amperometric biosensor based on parallel substrate conversion (catalase-peroxidase biochemical reactions), is presented. A nonlinear time independent coupled system of partial differential equations has been solved analytically using a new Homotopy perturbation method. Analytical expressions for substrate and product concentrations as function of single dimensionless parameter $A$ or $B$ are derived. The optimum value of $A$ or $B$ is also reported. The analytical expressions provided are much simpler and more efficient to understand and to predict the behavior of the system. Our analytical solution for substrates and products are compared with numerical solution providing consistent results. Concentration of substrates, products, and current depends upon reaction/diffusion parameters $\gamma_{S 1}, \gamma_{S 2}$, $\gamma_{S 3}, \gamma_{P 1}$, and $\gamma_{P 2}$. The response of the steady-state current with respect to all parameters is discussed. For all different concentrations, the analytical results matched well with the simulated result. The close matching of simulated result and the analytical data shows that our proposed solution is able to simulate the dynamic performance of sensing system using the parameters. The analytical results provided here are useful in sensor design, optimization, and prediction of electrode response.

\section{Appendices}

\section{A. Approximate Analytical Solution of the Nonlinear Equations (5)-(8) Using the Boundary Conditions (9) by New Homotopy Perturbation Method}

In this appendix, we indicated how to find the solution of (5)(8). We first construct the Homotopy as follows:

$$
\begin{gathered}
(1-p)\left[\frac{d^{2} S_{1 N}}{d y^{2}}-\gamma_{S 1} S_{1 N}-\gamma_{S 2} \frac{S_{1 N} S_{2 N}(1)}{\alpha S_{1 N}(1)+\beta S_{2 N}(1)}\right] \\
+p\left[\alpha S_{1 N} \frac{d^{2} S_{1 N}}{d y^{2}}+\beta S_{2 N} \frac{d^{2} S_{1 N}}{d y^{2}}-\alpha \gamma_{S 1} S_{1 N}^{2}\right. \\
\left.-\beta \gamma_{S 1} S_{1 N} S_{2 N}-\gamma_{S 2} S_{1 N} S_{2 N}\right]=0
\end{gathered}
$$

$$
\begin{aligned}
& (1-p)\left[\frac{d^{2} S_{2 N}}{d y^{2}}-\gamma_{S 3} \frac{S_{1 N}(1) S_{2 N}}{\alpha S_{1 N}(1)+\beta S_{2 N}(1)}\right] \\
& +p\left[\alpha S_{1 N} \frac{d^{2} S_{2 N}}{d y^{2}}+\beta S_{2 N} \frac{d^{2} S_{2 N}}{d y^{2}}-\gamma_{S 3} S_{1 N} S_{2 N}\right]=0 \\
& (1-p)\left[\frac{d^{2} P_{1 N}}{d y^{2}}-\frac{\gamma_{P 1} S_{1 N}}{2}\right]+p\left[\frac{d^{2} P_{1 N}}{d y^{2}}-\frac{\gamma_{P 1} S_{1 N}}{2}\right]=0 \\
& (1-p)\left[\frac{d^{2} P_{2 N}}{d y^{2}}-\gamma_{P 2} \frac{S_{1 N}(1) S_{2 N}}{\alpha S_{1 N}(1)+\beta S_{2 N}(1)}\right] \\
& +p\left[\alpha S_{1 N} \frac{d^{2} P_{2 N}}{d y^{2}}+\beta S_{2 N} \frac{d^{2} P_{2 N}}{d y^{2}}-\gamma_{P 2} S_{1 N} S_{2 N}\right]=0.3
\end{aligned}
$$

The boundary conditions are as follows:

$$
\begin{gathered}
\text { when } y=0 ; \quad \frac{d S_{1 N}}{d y}=\frac{d S_{2 N}}{d y}=\frac{d P_{2 N}}{d y}=0 ; \quad P_{1 N}=0, \\
\text { when } y=1 ; \quad S_{1 N}=S_{2 N}=1, \quad P_{1 N}=P_{2 N}=0 .
\end{gathered}
$$

The approximate analytical solutions of (A.1) to (A.4) are given by

$$
\begin{gathered}
S_{1 N}=S_{1 N 0}+p S_{1 N 1}+p^{2} S_{1 N 2}+\cdots \\
S_{2 N}=S_{2 N 0}+p S_{2 N 1}+p^{2} S_{2 N 2}+\cdots \\
P_{1 N}=P_{1 N 0}+p P_{1 N 1}+p^{2} P_{1 N 2}+\cdots \\
P_{2 N}=P_{2 N 0}+p P_{2 N 1}+p^{2} P_{2 N 2}+\cdots
\end{gathered}
$$

Substituting (A.6) into (A.1)-(A.4) and arranging the coefficients of powers $p$,

$$
\begin{aligned}
& p^{0}: \frac{d^{2} S_{1 N 0}}{d y^{2}}-\left(\gamma_{S 1}+\frac{\gamma_{S 2}}{\alpha+\beta}\right) S_{1 N 0}=0, \\
& p^{0}: \frac{d^{2} S_{2 N 0}}{d y^{2}}-\left(\frac{\gamma_{S 3}}{\alpha+\beta}\right) S_{2 N 0}=0, \\
& p^{0}: \frac{d^{2} P_{1 N}}{d y^{2}}+\frac{\gamma_{P 1}}{2} S_{1 N 0}=0, \\
& p^{0}: \frac{d^{2} P_{2 N}}{d y^{2}}-\left(\frac{\gamma_{S 3}}{\alpha+\beta}\right) S_{2 N 0}=0 .
\end{aligned}
$$

Solving (A.7) for the boundary conditions (A.5), we can find the following results:

$$
\begin{gathered}
S_{1 N 0}(y)=\frac{\cosh \left(\sqrt{\left(\gamma_{S 1}(\alpha+\beta)+\gamma_{S 2}\right) /(\alpha+\beta)} y\right)}{\cosh \left(\sqrt{\left(\gamma_{S 1}(\alpha+\beta)+\gamma_{S 2}\right) /(\alpha+\beta)}\right)}, \\
S_{2 N 0}(y)=\frac{\cosh \left(\sqrt{\gamma_{S 3} /(\alpha+\beta)} y\right)}{\cosh \left(\sqrt{\gamma_{S 3} /(\alpha+\beta)}\right)},
\end{gathered}
$$




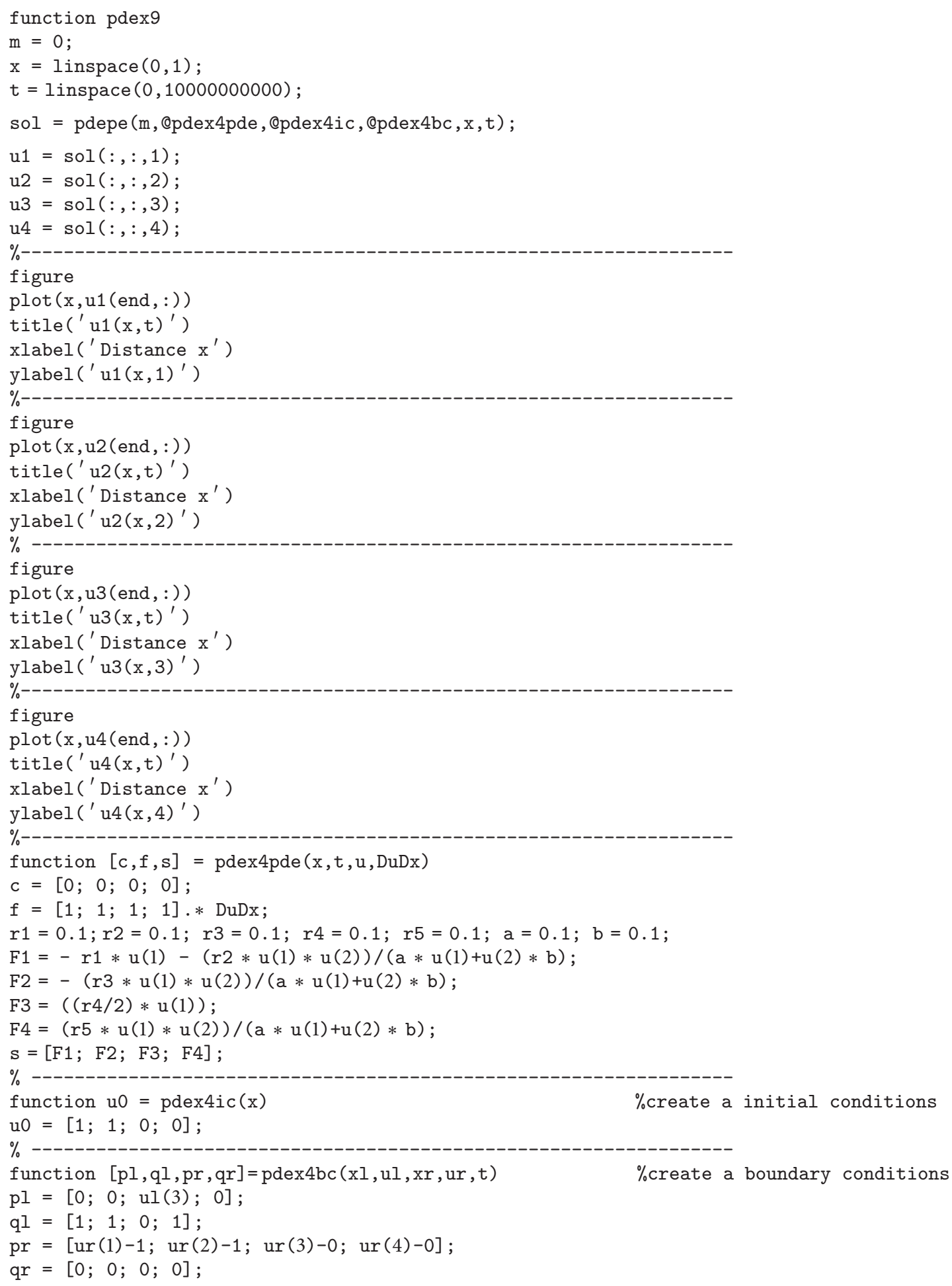

Algorithm 1: Matlab program to find the numerical solution of (5)-(8). 


$$
\begin{array}{r}
P_{1 N 0}(y)=\left[\gamma _ { P 1 } ( \alpha + \beta ) \left(-\cosh \left(\sqrt{\frac{\gamma_{S 1}(\alpha+\beta)+\gamma_{S 2}}{\alpha+\beta} y}\right)\right.\right. \\
+y \cosh \left(\sqrt{\frac{\gamma_{S 1}(\alpha+\beta)+\gamma_{S 2}}{\alpha+\beta}}\right) \\
-y+1) \\
\times\left(2\left(\gamma_{S 1}(\alpha+\beta)+\gamma_{S 2}\right)\right. \\
\left.\left.\quad \times \cosh \left(\sqrt{\frac{\gamma_{S 1}(\alpha+\beta)+\gamma_{S 2}}{\alpha+\beta}}\right)\right)^{-1}\right], \\
P_{2 N 0}(y)=-\frac{\cosh \left(\sqrt{\gamma_{S 3} /(\alpha+\beta)} y\right) \gamma_{P 2}}{\cosh \left(\sqrt{\gamma_{S 3} /(\alpha+\beta)}\right) \gamma_{S 3}}+\frac{\gamma_{P 2}}{\gamma_{S 3}} .
\end{array}
$$

Since it is a new approach to HPM, we need not to find further iterations. We consider $S_{1 N 0}, S_{2 N 0}, P_{1 N 0}$, and $P_{2 N 0}$ as the better approximate solutions. According to the HPM, we can conclude that

$$
\begin{aligned}
& S_{1 N}(y)=\lim _{p \rightarrow 1} S_{1 N}(y)=S_{1 N_{0}}+S_{1 N_{1}}+\cdots \approx S_{1 N_{0}}(y), \\
& S_{2 N}(y)=\lim _{p \rightarrow 1} S_{2 N}(y)=S_{2 N_{0}}+S_{2 N_{1}}+\cdots \approx S_{2 N_{0}}(y) \text {, } \\
& P_{1 N}(y)=\lim _{p \rightarrow 1} P_{1 N}(y)=P_{1 N 0}+P_{1 N 1}+P_{1 N 2}+\cdots \\
& \approx P_{1 N 0}(y) \text {, } \\
& P_{2 N}(y)=\lim _{p \rightarrow 1} P_{2 N}(y)=P_{2 N_{0}}+P_{2 N_{1}}+P_{2 N_{2}}+\cdots \\
& \approx P_{2 N_{0}}(y) \text {. }
\end{aligned}
$$

After putting (A.8) into (A.9), respectively, the final results can be described in (11) to (14) in the text.

\section{B. Matlab Program to Find the Numerical Solution of (5)-(8)}

See Algorithm 1.

\section{Nomenclature}

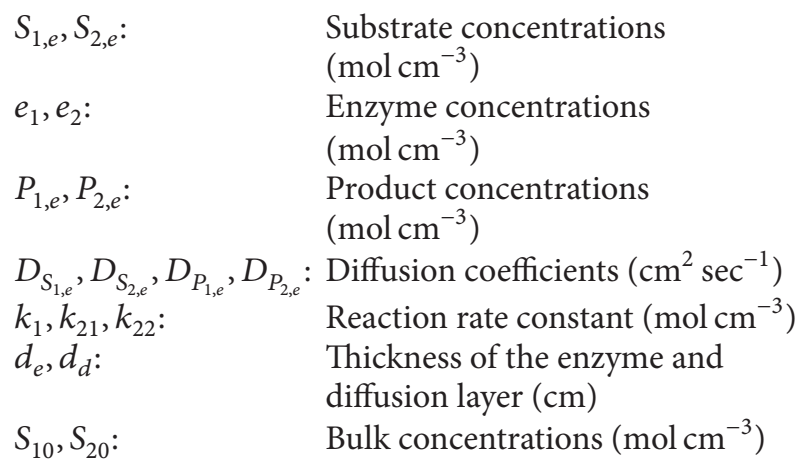

\author{
$x:$ Space $(\mathrm{cm})$ \\ $i$ : Current (Ampere). \\ Dimensionless Parameters (Greek Symbols)
}

$S_{1 N}, S_{2 N}$

$P_{1 N}, P_{2 N}$

$\gamma_{S 1}, \gamma_{S 2}, \gamma_{S 3}, \gamma_{P 1}, \gamma_{P 2}:$

$\alpha, \beta$ :

$y:$

$A=$

$\sqrt{\left(\gamma_{S 1}(\alpha+\beta)+\gamma_{S 2}\right) /(\alpha+\beta)}$ :

$B=\sqrt{\gamma_{S 3} /(\alpha+\beta)}$

Dimensionless substrate concentrations Dimensionless product concentrations Dimensionless reaction/diffusion parameters Dimensionless parameters Dimensionless space

Dimensionless parameter Dimensionless parameter.

\section{Conflict of Interests}

The authors declare that they have no conflict of interests regarding the publication of this paper.

\section{Acknowledgment}

This work was supported by the CSIR (no. 01 (2442)/10/EMRII), Government of India.

\section{References}

[1] A. Turner, G. Wilson, and I. Kaube, Biosensors: Fundamentals and Applications, Oxford University Press, Oxford, UK, 1987.

[2] F. W. Scheller, F. Schubert, and J. Fedrowitz, Frontiers in Biosensorics, Birkhauser, Basel, Switzerland, 1997.

[3] A. Sadana and N. Sadana, Handbook of Biosensors and Biosensor Kinetics, Elsevier, Amsterdam, The Netherlands, 2010.

[4] D. M. Fraser, Biosensors in the Body, Continuous in Vivo Monitoring, John Wiley and Sons, New York, NY, USA, 1997.

[5] L. S. Ferreira, M. B. De Souza Jr., J. O. Trierweiler, O. Broxtermann, R. O. M. Folly, and B. Hitzmann, "Aspects concerning the use of biosensors for process control: experimental and simulation investigations," Computers and Chemical Engineering, vol. 27, no. 8-9, pp. 1165-1173, 2003.

[6] J. R. D. Corcuera, R. Cavalieri, J. Powers, and J. Tang, "Amperometric enzyme biosensor optimization using mathematical modeling," in Proceeding of the/Case 18th Annual International Meeting (ASAE '04), page papers No. 047030, American Society of Agricultural Engineers, Ottawa, Canada, August 2004.

[7] C. Amatore, A. I. Oleinick, and I. Svir, "Construction of optimal quasi-conformal mappings for the 2D-numerical simulation of diffusion at microelectrodes. Part 1: principle of the method and its application to the inlaid disk microelectrode," Journal of Electroanalytical Chemistry, vol. 597, no. 1, pp. 69-76, 2006.

[8] I. Stamatin, C. Berlic, and A. Vaseashta, "On the computeraided modelling of analyte-receptor interactions for an efficient sensor design," Thin Solid Films, vol. 495, no. 1-2, pp. 312-315, 2006.

[9] L. D. Mell and J. T. Maloy, "A model for the amperometric enzyme electrode obtained through digital simulation and applied 
to the immobilized glucose oxidase system," Analytical Chemistry, vol. 47, no. 2, pp. 299-307, 1975.

[10] J. P. Kernevez, Enzyme Mathematics. Studies in Mathematics and Its Applications, Elsevier Science, Amsterdam, The Netherlands, 1980.

[11] J. Kulys, "The development of new analytical systems based on biocatalysts," Analytical Letters, vol. 14, article 377, 1981.

[12] P. N. Bartlett and K. F. E. Pratt, "Modelling of processes in enzyme electrodes," Biosensors and Bioelectronics, vol. 8, no. 9-10, pp. 451-462, 1993.

[13] M. E. G. Lyons, J. C. Greer, C. A. Fitzgerald, T. Bannon, and P. N. Barlett, "Reaction/diffusion with Michaelis-Menten kinetics in electroactive polymer films. Part 1. The steady-state amperometric response," Analyst, vol. 121, no. 6, pp. 715-731, 1996.

[14] P. Pérusse and D. Leech, "Dual electrode cyclic voltammetry under computer control using graphical programming of a bipotentiostat," Instrumentation Science and Technology, vol. 28, no. 1, pp. 59-70, 2000.

[15] J. J. Kulys, V. V. Sorochinskii, and R. A. Vidziunaite, “Transient response of bienzyme electrodes," Biosensors, vol. 2, no. 3, pp. 135-146, 1986.

[16] V. V. Sorochinskii and B. I. Kurganov, "Steady-state kinetics of cyclic conversions of substrate in amperometric bienzyme sensors," Biosensors and Bioelectronics, vol. 11, no. 3, pp. 225-238, 1996.

[17] T. Schulmeister, J. Rose, and F. Scheller, "Mathematical modelling of exponential amplification in membrane-based enzyme sensors," Biosensors and Bioelectronics, vol. 12, no. 9-10, pp. 10211030, 1997.

[18] A. Neykov and V. Rangelova, "Mathematical modeling of the biosensor systems," Biotechnology and Biotechnological Equipment, vol. 1998, no. 2, pp. 100-109, 1998.

[19] R. Baronas, F. Ivanauskas, and J. Kulys, "Modelling a biosensor based on the heterogeneous microreactor," Journal of Mathematical Chemistry, vol. 25, no. 2-3, pp. 245-252, 1999.

[20] W. F. Ames, Numerical Methods for Partial Differential Equations, Academic Press, New York, NY, USA, 2nd edition, 1977.

[21] A. Eswari and L. Rajendran, "Analytical solution of steady state current at a microdisk biosensor," Journal of Electroanalytical Chemistry, vol. 641, no. 1-2, pp. 35-44, 2010.

[22] P. Manimozhi, A. Subbiah, and L. Rajendran, "Solution of steady-state substrate concentration in the action of biosensor response at mixed enzyme kinetics," Sensors and Actuators, B: Chemical, vol. 147, no. 1, pp. 290-297, 2010.

[23] A. Meena and L. Rajendran, "Mathematical modeling of amperometric and potentiometric biosensors and system of nonlinear equations-homotopy perturbation approach," Journal of Electroanalytical Chemistry, vol. 644, no. 1, pp. 50-59, 2010.

[24] A. Eswari and L. Rajendran, "Analytical solution of steady-state current an enzyme-modified microcylinder electrodes," Journal of Electroanalytical Chemistry, vol. 648, no. 1, pp. 36-46, 2010.

[25] S. Loghambal and L. Rajendran, "Mathematical modeling in amperometric oxidase enzyme-membrane electrodes," Journal of Membrane Science, vol. 373, no. 1-2, pp. 20-28, 2011.

[26] A. Eswari and L. Rajendran, "Analytical expressions pertaining to the concentration of catechol, o-quinone and current at PPOmodified microcylinder biosensor for diffusion-kinetic model," Journal of Electroanalytical Chemistry, vol. 660, no. 1, pp. 200208, 2011.

[27] K. Venugopal, A. Eswari, and L. Rajendran, "Mathematical model for steady state current at PPO-modified micro-cylinder biosensors," Journal of Biomedical Science and Engineering, vol. 4, pp. 631-641, 2011.

[28] L. Rajendran and S. Anitha, "Reply to 'Comments on analytical solution of amperometric enzymatic reactions based on HPM ", Electrochimica Acta, vol. 102, pp. 474-476, 2013.

[29] V. Aseris, R. Baronas, and J. Kulys, "Modeling the biosensor utilizing parallel substrate conversion," Journal of Electroanalytical Chemistry, vol. 685, pp. 63-71, 2012.

[30] J.-H. He, "Application of homotopy perturbation method to nonlinear wave equations," Chaos, Solitons and Fractals, vol. 26, no. 3, pp. 695-700, 2005.

[31] Q. K. Ghori, M. Ahmed, and A. M. Siddiqui, "Application of homotopy perturbation method to squeezing flow of a newtonian fluid," International Journal of Nonlinear Sciences and Numerical Simulation, vol. 8, no. 2, pp. 179-184, 2007.

[32] T. Öziş and A. Yildirim, "A comparative study of He's homotopy perturbation method for determining frequency-amplitude relation of a nonlinear oscillator with discontinuities," International Journal of Nonlinear Sciences and Numerical Simulation, vol. 8, no. 2, pp. 243-248, 2007.

[33] S.-J. Li and Y.-X. Liu, "An improved approach to nonlinear dynamical system identification using PID neural networks," International Journal of Nonlinear Sciences and Numerical Simulation, vol. 7, no. 2, pp. 177-182, 2006.

[34] M. M. Mousa and S. F. Ragab, "Application of the homotopy perturbation method to linear and nonlinear schrödinger equations," Zeitschrift fur Naturforschung- A Journal of Physical Sciences, vol. 63, no. 3-4, pp. 140-144, 2008.

[35] J. H. He, "Homotopy perturbation technique," Computer Methods in Applied Mechanics and Engineering, vol. 178, pp. 257-262, 1999.

[36] R. D. Skeel and M. Berzins, "A method for the spatial discretization of parabolic equations in one space variable," SIAM Journal on Scientific \& Statistical Computing, vol. 11, pp. 1-32, 1990.

[37] "MATLAB 6. 1, The Math Works Inc., Natick, MA," 2000, http://www.scilabenterprises.com. 

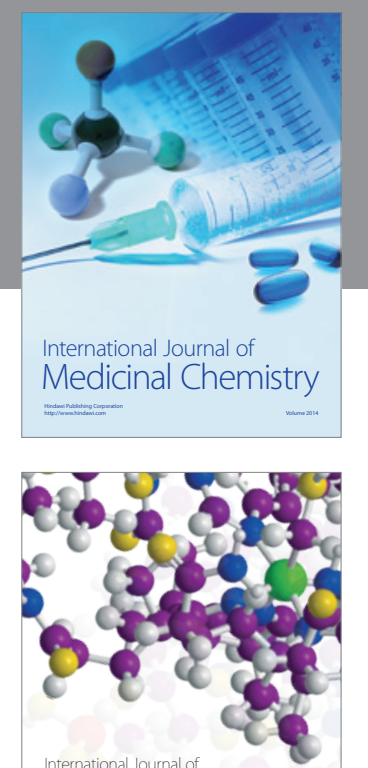

\section{Carbohydrate} Chemistry

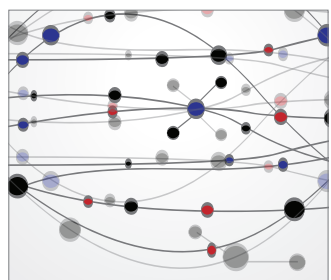

The Scientific World Journal
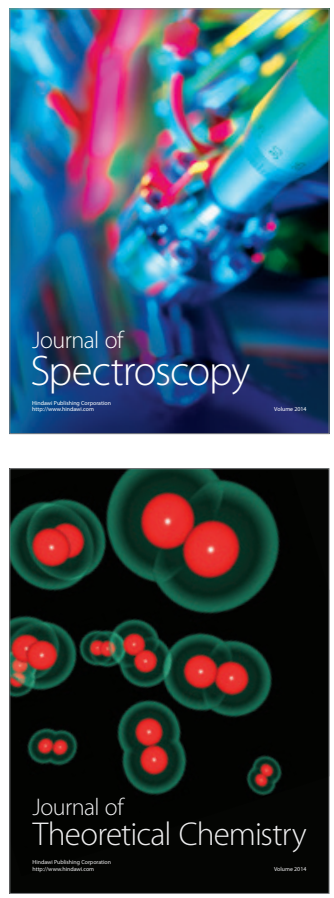
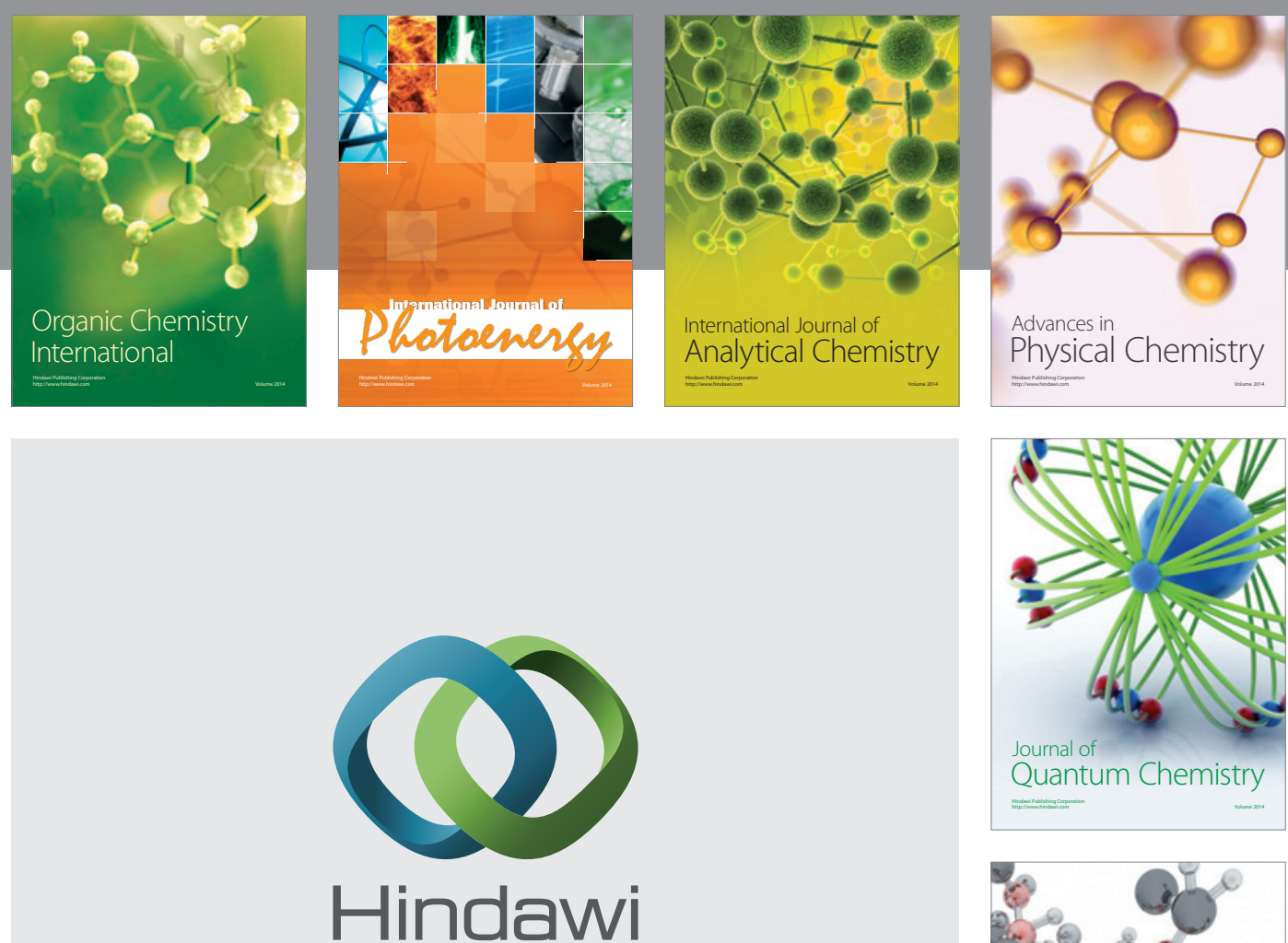

Submit your manuscripts at

http://www.hindawi.com

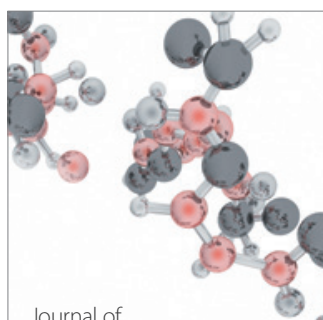

Analytical Methods

in Chemistry

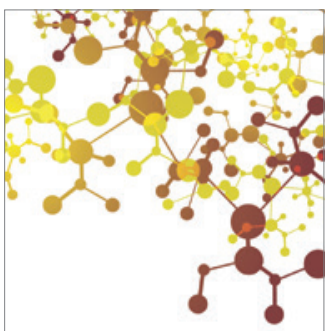

Journal of

Applied Chemistry

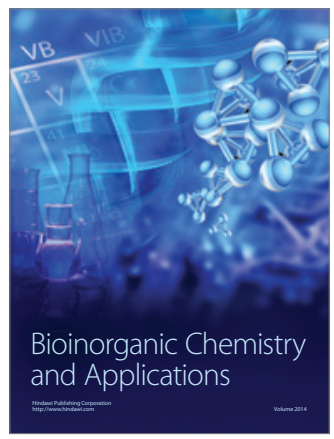

Inorganic Chemistry
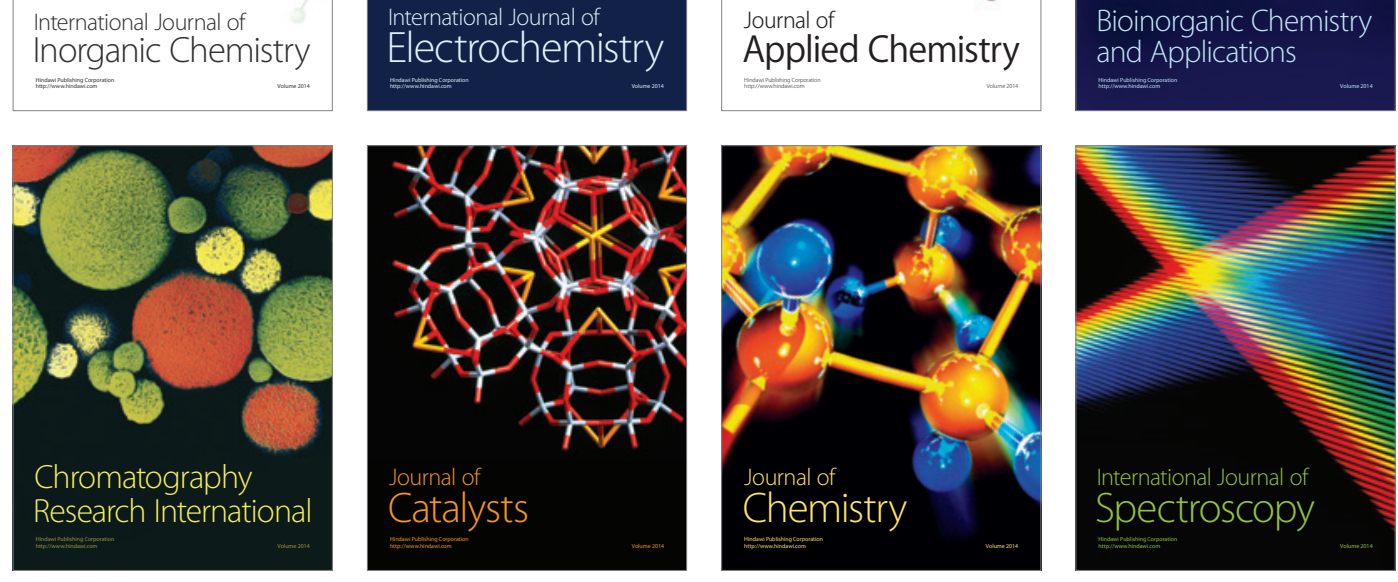